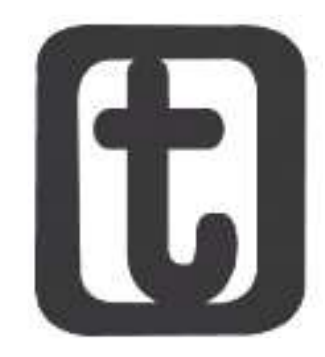

\title{
ANÁLISE DAS PRODUÇÕES DISCENTES NOS PROGRAMAS DE PÓS-GRADUAÇÃO EM SERVIÇO SOCIAL SOBRE PRISÕES
}

\author{
Analysis of discussion productions in post-graduation programs in social work on prisons
}

\author{
João Rafael da Conceição*
}

\section{RESUMO}

Este trabalho visa apresentar os dados referentes à pesquisa sobre o estado da arte nos Programas de Pósgraduação em Serviço Social, no Brasil, acerca das prisões, entre 2014 e 2017, assim como hipóteses iniciais frente aos resultados obtidos a partir da pesquisa documental nos resumos disponíveis na Plataforma Sucupira. Como resultados parciais, apreenderam-se lacunas e tendências gerais: concentração de estudos nas áreas temáticas de execução da pena, reflexão teórica e gênero, persistência da incipiência de pesquisas sobre o trabalho profissional, produção contínua de temas afins em torno de $1 \%$ e concentração de defesas das produções nas regiões sul e sudeste.

\section{PALAVRAS-CHAVE}

Produções discentes; Serviço Social; Prisões.

\begin{abstract}
This paper aims to present the data about the state of the art research in the Social Work Postgraduate Programs in Brazil, about prisons between 2014 and 2017, as well as initial hypotheses regarding the results obtained from documentary research in summaries available on the Sucupira Platform. As partial results, general gaps and tendencies were apprehended: concentration of studies in thematic areas of execution of the sentence, theoretical reflection and gender, persistence of incipience of research on professional work, continuous production of related subjects around $1 \%$ and concentration of defenses of productions in the south and southeast regions.
\end{abstract}

\section{KEYWORDS}

Student productions; Social Work; Prisons.

Submetido em: 13/1/2019.

Revisto em: 22/6/2019.

Aceito em: 8/7/2019.

\footnotetext{
* Assistente Social. Mestre em Serviço Social pela Pontifícia Universidade Católica do Rio de Janeiro. Residente em Serviço Social pelo Programa de Residência Multiprofissional em Saúde da Mulher na Universidade Federal do Rio de Janeiro. Av. Pres. Vargas, 2863 - Centro, Rio de Janeiro - RJ, 20210-030. ORC ID: https://orcid.org/0000-0003-3485-826X E-mail: <jonh.unirio@gmail.com>.
}

DOI 10.22422/temporalis.2019v19n37p172-187 Commons Atribuição 4.0 Internacional (https://creativecommons.org/licenses/by/4.o/deed.pt_BR), que permite copiar e redistribuir o material em qualquer suporte ou formato, bem como adaptar, transformar e criar a partir deste material para qualquer fim, mesmo que comercial. O licenciante não pode revogar estes direitos desde que você respeite os termos da licença. 


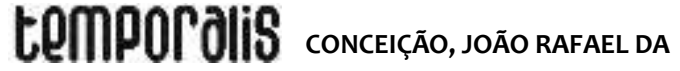

\section{INTRODUÇÃO}

\begin{abstract}
A depta de retóricas como os ideais re (ressocialização, reintegração e reeducação), 1 da retribuição (sensação de justiça, a punição como fim em si mesma) e da prevenção (em relação a novos crimes), a política penal ${ }^{1}$ expressa um conjunto de ações profissionais irreflexivas, empiricistas e de apologias indiretas. Conjuga-se ao referido processo o famigerado discurso de impunidade, o clamor penal, a seletividade penal, a estética do horror, as condições desumanas, degradantes e cruéis das prisões.
\end{abstract}

Lócus de atuação profissional desde a década de 1940, a trajetória do Serviço Social nas instituições prisionais é marcada pelo assistencialismo e, igualmente, pelo "tratamento penal". Ao Serviço Social, nas distintas unidades prisionais, compete funções que variam entre avaliação social para fins judiciais e/ou processos avaliativos institucionais; acompanhamento/orientação; apoio no meio externo/articulação; planejamento; saúde; e recursos humanos/gestão institucional (CONSELHO FEDERAL DE SERVIÇO SOCIAL, 2014).

Segundo o Departamento Penitenciário Nacional (BRASIL, 2014), apenas 62\% das unidades têm sala de atendimento, sendo apenas 37\% delas exclusivas ao Serviço Social - possível indicativo de violação ao direito profissional de sigilo. A proporção de pessoas presas nas instituições prisionais brasileiras em relação ao número de assistentes sociais em 2016 era de 520 pesos para cada profissional (BRASIL, 2017).

Frente a este quadro, inquieta-se acerca de tendências e lacunas nas produções acadêmicas em relação ao lócus de atuação supracitado nos programas de pós-graduação em Serviço Social. Este trabalho, portanto, busca apresentar os dados parciais dos resultados alcançados por uma pesquisa no Banco de Teses e Dissertações da Coordenação de Aperfeiçoamento de Pessoal de nível superior (CAPES).

Como marco temporal, optou-se pelo período entre 2014 e 2017. Este período corresponde (i) ao triênio das gestões dos Conselhos Regionais e Federal de Serviço Social que deliberaram pela abertura do debate sobre uma sociedade sem prisões - problemática relevante e contra-hegemônica frente ao fenômeno da seletividade penal, do superencarceramento, do clamor penal e do crescimento de propostas legislativas de recrudescimento penal; e (ii) à criação da Plataforma Sucupira da CAPES, que disponibiliza virtualmente os resumos ${ }^{2}$ - em alguns casos até toda a produção em Portable Document Format (PDF).

Tal levantamento visa identificar lacunas e tendências gerais abordadas nos estudos da problemática em questão: a produção acadêmica sobre as prisões nas pós-graduações da área do Serviço Social3. Pressupõe-se que os trabalhos acadêmicos das pós-graduações têm relevância, originalidade e validade, seguidas de aprovações rigorosas.

\footnotetext{
${ }^{1}$ A política penal constitui parte do tripé da Justiça Criminal, na qual se somam a política penal, a segurança pública e o Poder Judiciário.

2 "A compilação de informações em meios eletrônicos é um grande avanço para os pesquisadores, democratizando o acesso e proporcionando atualização frequente" (SOUZA; SILVA; CARVALHO, 2010, p. 103). ${ }^{3}$ Ao todo são 34 programas de pós-graduação espalhados por todas as regiões do país: "23 em Serviço Social (67,6\%); 06 em Política Social (17,6\%); 03 em Políticas Públicas (8,8\%), e 02 em Economia Doméstica (5,9\%). À exceção dos 2 Programas de Economia Doméstica, todos os 32 Programas de Pós-Graduação guardam interlocução com o objeto do Serviço Social e suas interfaces com a política social e as políticas públicas. Em
}

Temporalis, Brasília (DF), ano 19, n. 37, p. 172-187, jan./jun. 2019. | ISSN 2238-1856 
Assim, apreender lacunas e tendências gerais da problemática em questão pode vir a contribuir para reflexões profissionais sobre o tema, que poderão incidir no trabalho profissional de assistentes sociais nas prisões, este armazém de gente violador de direitos e de condições degradantes e desumanas, assim como empreender esforços para deslegitimar a política penal e construir a assertiva da necessidade de um mundo sem prisões.

Nesse sentido, o artigo se organiza em três partes: (i) da metodologia, que se apresenta o percurso metodológico adotado; (ii) dos resultados parciais, que se expõem as produções temáticas encontradas, as discussões e hipóteses iniciais e a problemática das lacunas; e (iii) das considerações finais.

\section{DA METODOLOGIA}

De cunho exploratório, a pesquisa estruturou-se a partir da pesquisa documental. Por meio dos resumos das teses e dissertações disponíveis na Plataforma Sucupira (e nos sítios eletrônicos dos programas de pós-graduação), realizaram-se a quantificação e a identificação de lacunas e possíveis tendências da pesquisa em Serviço Social sobre a área do sistema prisional no país entre 2014 e 2017.

As fases constituintes da metodologia proposta foram:

1. Coleta e compilação dos dados;

2. leitura dos resumos;

3. análise de conteúdo;

4. agrupamento por recorte temático;

5. interpretação dos dados obtidos.

A pesquisa documental consistiu na análise do contexto, na identificação do autor, na verificação da procedência do documento, na consideração do tipo de documento, na delimitação/apreensão de conceitos-chaves e na interpretação inicial dos dados obtidos.

Durante a sistematização de dados, no intuito de agrupá-los de acordo com a predominância do conteúdo, 05 resumos não foram encontrados na Plataforma Sucupira nem no banco de teses e dissertações do próprio programa.

O quadro I ilustra a distribuição das produções discentes sobre temas afins ao aprisionamento, entre 2014 e 2017, nos programas de pós-graduação em Serviço Social no Brasil.

sua composição, os 32 Programas possuem docentes graduados ou com Doutorado em Serviço Social (49,4\%)" (COORDENAÇÃO DE APERFEIÇOAMENTO DE PESSOAL DE NÍVEL SUPERIOR, 2017, p. 4-5).

Temporalis, Brasília (DF), ano 19, n. 37, p. 172-187, jan./jun. 2019. | ISSN 2238-1856 
Quadro 1 - Distribuição das produções discentes sobre temas afins ao aprisionamento, entre 2014 e 2017, nos Programas de Pós-graduação em Serviço Social no Brasil.

\begin{tabular}{|c|c|c|}
\hline Instituições/Programas & Tese & Dissertação \\
\hline $\begin{array}{l}\text { EMESCAM/Políticas Públicas e } \\
\text { Desenvolvimento Local }\end{array}$ & & 1 \\
\hline PUC Rio/Serviço Social & & 1 \\
\hline PUC RS/Serviço Social & & 4 \\
\hline PUC SP/Serviço Social & 2 & 2 \\
\hline UCPEL/Política Social & & 3 \\
\hline $\begin{array}{l}\text { UECE/Serviço Social, Trabalho e Questão } \\
\text { Social }\end{array}$ & & 1 \\
\hline UEL/Serviço Social e Política Social & & 1 \\
\hline UERJ/Serviço Social & & 1 \\
\hline UFAL/Serviço Social & & 1 \\
\hline UFES/Política Social & & 1 \\
\hline UFF/Política Social & & 1 \\
\hline UFMT/Política Social & & 2 \\
\hline UFPB/Serviço Social & & 1 \\
\hline UFPE/Serviço Social & 1 & \\
\hline UFRJ/Serviço Social & 1 & 5 \\
\hline UNB/Política Social & & 2 \\
\hline UNESP/Serviço Social & & 2 \\
\hline UNIOESTE/Serviço Social & & 2 \\
\hline
\end{tabular}

Fonte: CAPES (2018). Elaboção própria.

A seguir, apresentam-se os resultados parciais e as discussões iniciais, com indicações de hipóteses em relação às tendências encontradas e lacunas percebidas.

\section{DOS RESULTADOS PARCIAIS}

Dados da CAPES (2018) expõem que, entre 2014 e 2017, as pós-graduações da área de Serviço Social defenderam o total de 1855 teses e dissertações, que representaram 0,67\% do total de produções acadêmicas, de todas as áreas de produção do conhecimento, registradas na referida Coordenação, abaixo comparadas ${ }^{4}$ no gráfico I.

\footnotetext{
${ }^{4}$ Entre 2014 e 2017, ao todo foram defendidas 275.927 teses e dissertações, segundo dados recolhidos no sítio eletrônico da CAPES em 24 de janeiro de 2018.
}

Temporalis, Brasília (DF), ano 19, n. 37, p. 172-187, jan./jun. 2019. | ISSN 2238-1856 


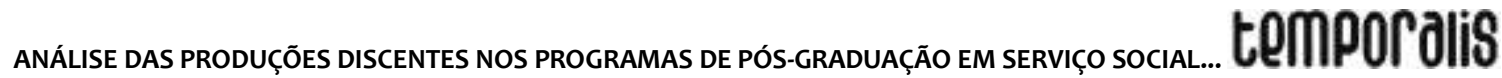

Gráfico 1 - Relação entre total de produções e produções na área de serviço social, entre 2014 e 2017.

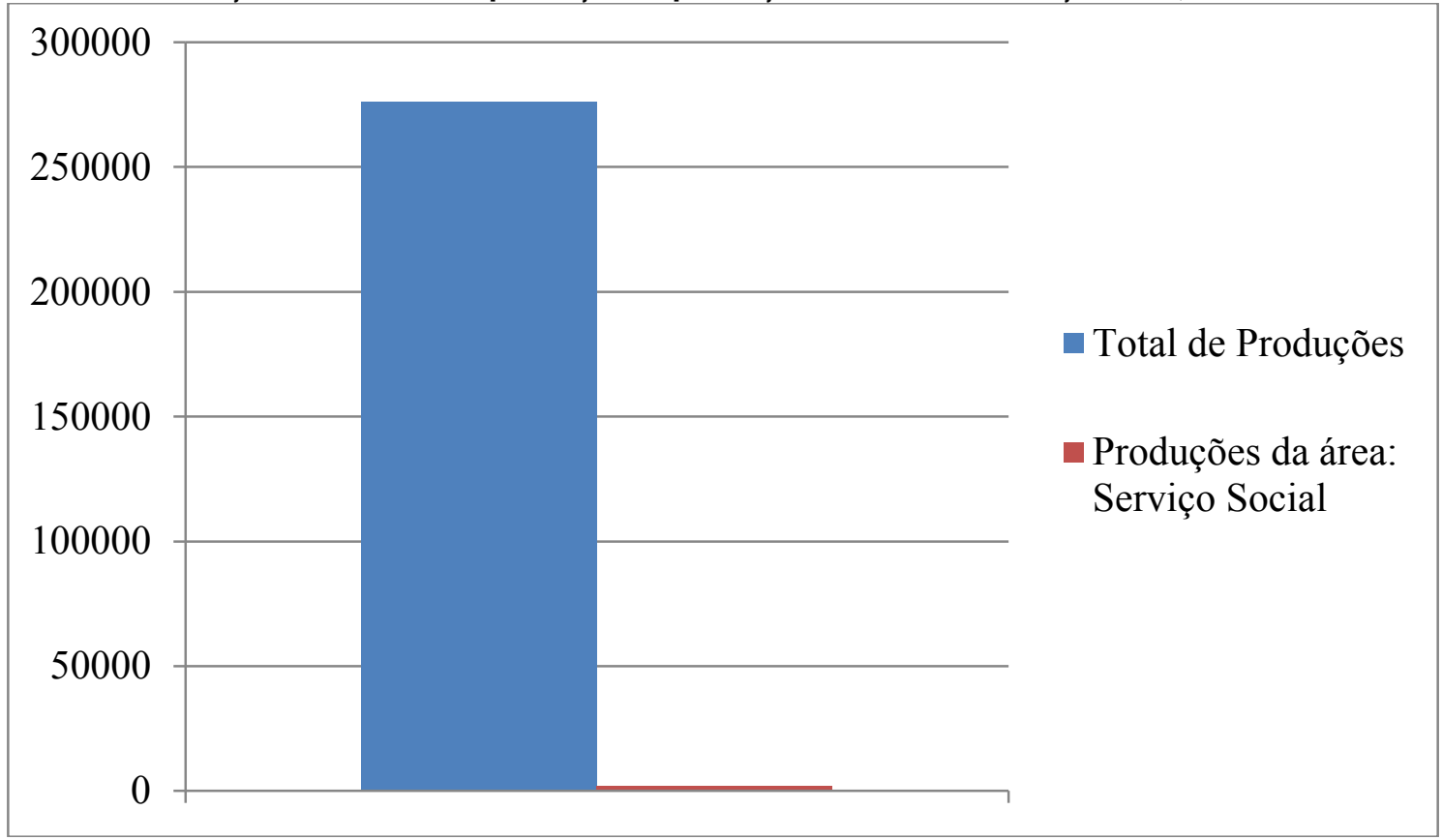

Fonte: CAPES (2018). Elaboração própria.

Acerca do total de produções defendidas na área de Serviço Social, percebe-se uma queda vertiginosa, em torno de 50\% em 2017 em relação aos anos anteriores: em janeiro de 2018, os dados da CAPES (2018) registraram defesas de 525 teses e dissertações em 2014; de 546 em 2015; de 524 em 2016; e de 260 em 2017.

Em relação à problemática em questão, a coleta de dados encontrou uma amostra de 35 teses e dissertações consideradas pertinentes aos objetivos do estudo, utilizando-se dos seguintes descritores: abolicionismo penal; aprisionamento; cárcere; custódia; egresso; medida de segurança; pena; penitenciária; punição; preso/presa; prisão; privação/privada/privativa de liberdade; sistema penitenciário/prisional.

Por critério de pertinência, ou seja, de adequação das teses e dissertações analisadas aos objetivos da pesquisa, apreendeu-se os trabalhos que abordassem o cárcere, a pena privativa de liberdade e temas afins em torno da imputabilidade e medida de segurança para adultos, incluindo os egressos e os impactos no convívio sociofamiliar.

Assim, as produções sobre prisões representaram 1,94\% da produção acadêmica dos programas de Serviço Social, sintetizadas no quadro II.

O quadro II ilustra uma proporção contínua de produções com a problemática pertinente em torno de 1\% e uma elevação incomum em 2015 (as produções daquele ano duplicaram em relação ao ano anterior e aos subsequentes). Percebe-se, porém, que a proporção geral é relativamente baixa, frente a um lócus profissional tão complexo como o sistema prisional. Igualmente, visualiza-se uma lateralização de produções sobre o trabalho profissional propriamente, não ultrapassando uma produção anual e não havendo produção com estas características em 2017. 
Quadro 2: Proporção de produções temáticas por ano em relação ao total de produções na área de serviço social entre 2014 E 2017.

\begin{tabular}{|c|c|c|c|}
\multirow{2}{*}{ ANO } & $\begin{array}{c}\text { TOTAL DE } \\
\text { PUBLICAÇÕES }\end{array}$ & $\begin{array}{c}\text { PRODUÇÕES } \\
\text { TEMÁTICAS }\end{array}$ & PROPORÇÃO DE PRODUÇÕES TEMÁTICAS \\
2014 & 525 & 8 & $1,71 \%$ \\
\cline { 2 - 4 } 2015 & 546 & 17 & $3,11 \%$ \\
2016 & 524 & 7 & $1,34 \%$ \\
\cline { 2 - 4 } 2017 & 260 & 3 & $1,15 \%$ \\
\cline { 2 - 4 } & \multicolumn{2}{|c|}{ PROPORÇÃO GERAL (2014/2017) } & $1,94 \%$ \\
\hline
\end{tabular}

Fonte: CAPES (2018). Elaboração própria.

Em termos de concentração territorial de produções, as regiões Sul e Sudeste têm demonstrado preocupação especial, superior à distribuição proporcional dos programas de pós-graduação na área do Serviço Social. Percebe-se a pouquíssima relação entre as produções temáticas e os programas, população carcerária e o quantitativo de profissionais atuantes no sistema prisional da região. A região Norte corrobora para a hipótese desta pouquíssima relação, visto que nenhum de seus programas tiveram defesas de produções na temática pertinente. O mesmo ocorre no Nordeste: as produções defendidas na região estiveram bastante aquém da proporção de programas, população carcerária e o quantitativo de profissionais. As hipóteses para os dados apresentados, a seguir, no Quadro III é a possibilidade de concentração de pesquisadores que sejam referência na área nas regiões Sul e Sudeste, assim como pode indicar uma relação com a execução da política de segurança pública nas regiões em questão, em especial o Sudeste, que apresenta a maior concentração de população carcerária do país.

Quadro 3: Distribuição por região das publicações, dos programas de pós-graduação, da população carcerária e do assistente social.

\begin{tabular}{|c|c|c|c|c|}
\hline REGIÃO DO PAÍS & $\begin{array}{l}\text { PRODUÇÕES } \\
\text { TEMÁTICAS }\end{array}$ & $\begin{array}{l}\text { PROGRAMAS DE } \\
\text { PÓS-GRADUACCÃO } \\
\text { STRICTO SENSU5 }\end{array}$ & $\begin{array}{l}\text { POPULAÇÃO } \\
\text { CARCERÁRIA }\end{array}$ & $\begin{array}{l}\text { ASSISTENTES } \\
\text { SOCIAIS }\end{array}$ \\
\hline CENTRO-OESTE & $11,11 \%$ & $9 \%$ & $8,42 \%$ & 89 \\
\hline NORDESTE & $11,11 \%$ & $33,3 \%$ & $17,85 \%$ & 244 \\
\hline NORTE & $0 \%$ & $6 \%$ & $6,92 \%$ & 167 \\
\hline SUDESTE & $50 \%$ & $36,4 \%$ & $52,02 \%$ & 262 \\
\hline SUL & $27,78 \%$ & $15,2 \%$ & $14,73 \%$ & 183 \\
\hline
\end{tabular}

Fonte: CAPES (2017; 2018); Brasil (2014; 2017). Elaboração própria.

Em uma síntese analítica inicial dos conteúdos dos resumos, constataram-se alguns pontos que merecem destaques para posteriores reflexões, que fogem dos objetivos do presente artigo:

\footnotetext{
${ }^{5}$ Baseado em Coordenação de Aperfeiçoamento de Pessoal de Nível Superior (2017).

${ }^{6}$ Refere-se aos dados do Ministério da Justiça e Segurança Pública (BRASIL, 2017).

7 Os dados do Ministério da Justiça e Segurança Pública (BRASIL, 2017) manifestam o quantitativo total de assistentes sociais, contudo sem sua distribuição por unidade federativa ou por região do país. Para esta parte do quadro, optou-se por utilizar os dados do Ministério da Justiça (BRASIL, 2014) que, embora os Estados de RJ, SP e RR não informassem o número de assistentes sociais, tem-se a distribuição por Estados dos assistentes sociais que atuam nas unidades prisionais do Brasil, fornecendo uma aproximação da realidade regional.
}

Temporalis, Brasília (DF), ano 19, n. 37, p. 172-187, jan./jun. 2019. | ISSN 2238-1856 
anÁlise das PRoduções discentes nos programas de pós-graduação em Serviç̧o social...

i. Prevalência de produções acadêmicas de abordagem qualitativa e interesse exploratório, com recurso à pesquisa documental (cartas, documentos oficiais e legislações pertinentes) e de campo, em especial com as técnicas de questionários, entrevistas e grupos focais. Alguns poucos se utilizaram da observação participante, do diário de campo e da história oral;

ii. Ampla dificuldade de delimitação/apreensão dos conceitos-chaves adotados por parte significativa das produções acadêmicas. Nas poucas produções em que se puderam apreender os conceitos-chaves, houve destaque para os seguintes: criminalização, estigma, controle social, seletividade. Outros foram encontrados, ainda que especificamente em um ou outro resumo, tais como o paradigma da complexidade e a sociologia das ausências e emergências;

iii. Predomínio de resumos de produções que afirmaram partir da criminologia crítica em suas análises teóricas, inclusive houve aqueles que citaram articular com outras correntes da criminologia, como a queer, a feminista e a latino-americana. Houve consideravelmente aqueles que não citaram sua fundamentação teórica.

iv. Ainda que em menor proporção, houve trabalhos que reivindicavam as retóricas dos ideais re (em especial, a reintegração social).

Esses destaques, em especial os itens (ii), (iii) e (iv), dão indícios de ecletismo ${ }^{8}$ em parte significativa das produções acadêmicas de pós-graduação em Serviço Social sobre prisões. Indícios devido aos limites da própria pesquisa, que se propõe a analisar tendências e lacunas nas produções acadêmicas a partir de seus resumos.

Analisado inicialmente o conteúdo dos resumos, as produções encontradas foram agrupadas por recortes temáticos predominantes, a saber: diversidade sexual; egressos; execução da pena; família; gênero; geração; medida de segurança; reflexão teórica; e religião, chegando-se aos seguintes números e caracterizações:

- Diversidade Sexual: versa sobre os estudos acerca de experiências vivenciadas pela população LGBT no interior das prisões (01).

- Egresso: compreende os ensaios que analisaram a realidade e os desafios dos egressos do sistema prisional (03).

- Execução da Pena: são os trabalhos que se debruçaram nos aspectos qualitativos da execução penal, cuja premissa é apreender a relação entre o plano normativo e a realidade concreta. Encontram-se trabalhos sobre a saúde da população privada de liberdade (01); acesso e/ou violação de direitos (02); os regimes e as penas alternativas (02); a gestão da prisão (01); o trabalho extramuros (01); e o trabalho profissional de assistentes sociais (01).

- Família: busca compreender a realidade da família frente à situação de ter um ente querido detento (01).

\footnotetext{
8 Para Rocha (2005), a postura eclética mescla pensamentos e correntes teóricas antagônicas, cujo desdobramento sociopolítico é o consenso entre as classes sociais fundamentais.
}

Temporalis, Brasília (DF), ano 19, n. 37, p. 172-187, jan./jun. 2019. | ISSN 2238-1856 
- Gênero: conforma os trabalhos que abordaram situações sobre as mulheres encarceradas a partir da perspectiva de agentes penitenciários e de sua capacitação para intervir na área (02); das influências do comércio e do uso de drogas ilícitas e sua distinção por gênero (04); da família monoparental (01); e dos determinantes para a reincidência de mulheres (01).

- Geração: versa sobre o encarceramento de idosos (01).

- Medida de Segurança: reúne as reflexões sobre os manicômios judiciários e a reinstitucionalização (01); e a atuação profissional na desinstitucionalização (01).

- Reflexão Teórica: consiste nos estudos que se concentram em análises teóricas e políticas sobre o estado da arte sobre o sistema penal (01); o controle social (03); a criminalização da pobreza e o rebatimento nas prisões (02); as vítimas da guerra contra as drogas (01); fim das prisões (01); drogas e abolicionismo penal (01); encarceramento em massa (01).

- Religião: articula Serviço Social e assistência religiosa (01); e assistência religiosa e reintegração (01).

O gráfico 2 ilustra o quantitativo total de produções acadêmicas (35) por recorte temático.

Gráfico 2 - Produções temáticas por recorte.

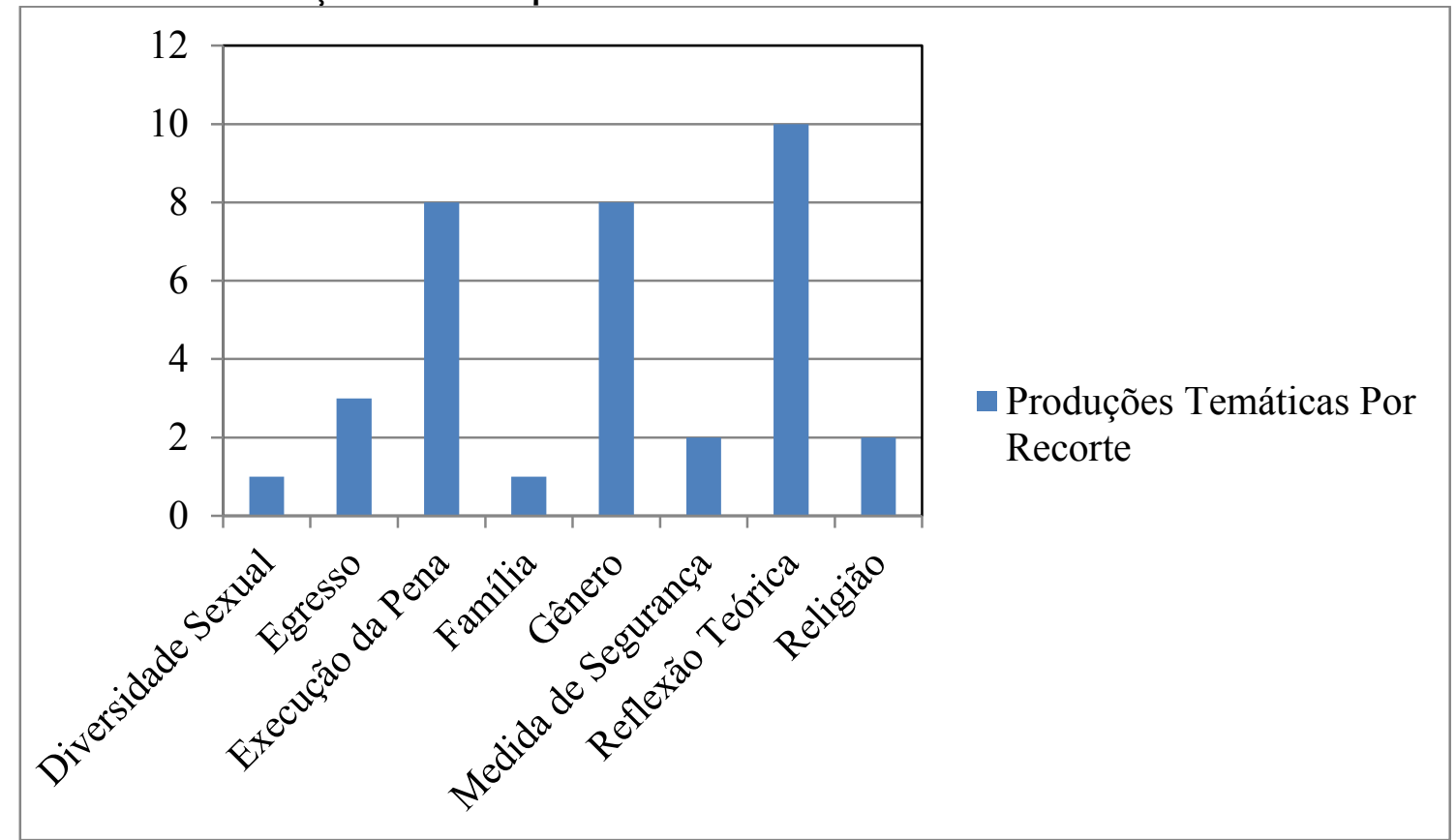

Fonte: CAPES (2018). Elaboração própria.

Em relação ao gráfico II, nota-se que execução da pena, gênero e reflexão teórica, quando agregadas, somam $72,22 \%$ das produções. No entanto, foram temas de extensa pluralidade interna, com objetos bem dispersos entre si, embora estejam no mesmo recorte temático, como pôde ser visualizado na caracterização dos recortes temáticos. Por sua vez, o recorte medida de segurança teve apenas dois trabalhos que, curiosamente, versaram sobre os processos de saída e retorno ao manicômio judiciário, ou seja, os processos de institucionalização e desinstitucionalização.

Temporalis, Brasília (DF), ano 19, n. 37, p. 172-187, jan./jun. 2019. | ISSN 2238-1856 


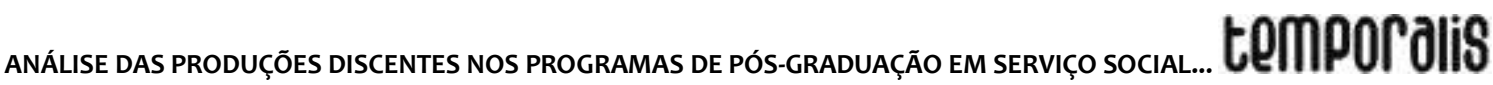

Percebe-se, igualmente, a lacuna de debates sobre: (i) o imigrante preso; (ii) a diversidade étnica e racial; (iii) a privatização, terceirização e parcerias público-privadas da administração/gestão e dos serviços e assistências oferecidos; (iv) as organizações, coletivos e movimentos em defesa da pessoa privada de liberdade; (v) a saúde do trabalhador; (vi) as condições de trabalho, vínculo empregatício e representação de classe; dentre outros temas. Estas lacunas podem estar relacionadas à pequena quantidade de trabalhos produzidos até o momento deste levantamento.

Nas produções encontradas, também há pouquíssima articulação com o trabalho profissional de assistente social nas prisões e articulação com outras políticas sociais. Apenas $0,16 \%$ dos trabalhos estabelecerem diálogo com o exercício da profissão. Eram trabalhos de experiências bem particulares: Serviço Social na coordenação da assistência religiosa; Serviço Social no trabalho junto aos carcereiros; e Serviço Social na desinstitucionalização.

\section{Discussões e hipóteses iniciais}

No âmbito da execução da pena, embora os objetos específicos sejam diversos, percebe-se uma preocupação em estabelecer um nexo entre teoria e prática. Trata-se de um cuidado próprio das ciências sociais aplicadas. Acerca dessa relação, uma tese seminal é de Guindani (2001) sobre a dialética instituída e instituinte. Para além de compreender as normas práticas, as requisições institucionais e as demandas dos usuários, ou seja, a prática instituída, a prática instituinte requer uma análise da totalidade concreta e uma intervenção teleologicamente transformadora da realidade no horizonte da emancipação humana, a práxis profissional e social.

Das preocupações acerca do recorte temático gênero, apreende-se que entre 2000 e 2014 o crescimento da população carcerária feminina ultrapassou a proporção de 500\% (BRASIL, 2014). O encarceramento feminino causa indagações, igualmente, devido à majoritária tipificação criminal pela qual as mulheres são condenadas: a de comércio varejista de drogas ilícitas (no vulgo jurídico, o tráfico de drogas). A concentração significativa de estudos sobre gênero pode encontrar também uma de suas razões na influência dos movimentos feministas e de mulheres no Serviço Social. Resgatam-se, igualmente, os princípios do Código de Ética Profissional que põem como horizonte a construção de uma nova ordem societária livre de opressões, assim como o exercício profissional sem discriminação de qualquer natureza, entre elas a de gênero.

A busca pela causa do encarceramento pode ser uma das preocupações das reflexões teóricas, inclusive o questionamento da tese de unilateralidade ou da multiplicidade de causas para a quebra da licitude e a (pseudo) estabilidade da ordem, bem como as interrelações entre a manutenção do status quo, a criminalização da pobreza e o comércio varejista de drogas ilícitas. Estas análises não são estranhas aos estudos do Serviço Social. Ao assumir uma direção social contra-hegemônica, o Serviço Social adota o marxismo, que, nos termos de Lukács (2012), se trata de uma perspectiva teórica crítica e revolucionária, que, para a apreensão da realidade, insiste na análise da totalidade concreta e em mudanças substantivas da realidade social. 
Uma discussão necessária é sobre o inegável papel da religião no sistema prisional. Ela cumpre o papel do Estado em diversas frentes, sobretudo no âmbito da assistência material e na assistência ao egresso. No Rio de Janeiro, a maior parte das religiões credenciadas são cristãs, de matriz neopentecostal (CARVALHO, 2015). Uma prática instituída no sistema prisional fluminense, por exemplo, é a destinação de alas exclusivas a presos evangélicos. Existe a crença de que ao se assumir cristão elevam-se as chances de "ressocialização" e aumentam-se as redes socioassistenciais (GAMA, 2014). Segundo Gama (2014), a religião é uma saída sem ônus econômico ao Estado, porém abstrata. Igualmente, o relatório final do Grupo de Trabalho (GT) Conselho da Comunidade, organizado pelo Conselho Federal do Serviço Social, com participação de diversos conselhos regionais em Serviço Social, em 2011, constata que a Pastoral Carcerária, instituição vinculada à Igreja Católica, era a responsável pelos trabalhos do Conselho da Comunidade no Rio de Janeirog. Constata-se, assim, que não há laicidade no Estado, inclusive no interior dos espaços de violência estatal, como as prisões.

Os recortes temáticos em menor destaque, como os de diversidade sexual, egresso, família e geração, foram produções pontuais, em que se articulavam tais temas de alguma forma com experiências profissionais, embora não desvelassem o trabalho profissional propriamente, tampouco no sentido da sistematização da prática. Este termo, que carrega consigo uma preocupação histórica da profissão (ALMEIDA, 2006), inclusive, não é citado em nenhum dos resumos. Cada recorte, a seu modo e com sua metodologia específica, buscava analisar a situação e os desafios dos grupos pesquisados no processo de aprisionamento, institucionalização, desinstitucionalização e na realidade do egresso, bem como a experiência das famílias em relação à custódia de seu ente querido.

Causa-nos preocupação a persistência da incipiência de produções sobre o trabalho profissional: Almeida (idem) aponta esse distanciamento desde os anos de 1990. Ele expressa que são as monografias, de graduação e de pós-graduação lato sensu, que se preocupam em resgatar as experiências profissionais realizadas ou em curso.

\section{A problemática das lacunas}

Em termos de lacunas, expõem-se, a seguir, dados oficiais do Ministério da Justiça (BRASIL, 2014), do Ministério da Justiça e Segurança Pública (BRASIL, 2017) e do Ministério Público (BRASIL, 2016) para ilustrar parte da problemática ausente nas produções do Serviço Social analisadas no presente estudo - que não necessariamente é o mesmo quadro em outras áreas do conhecimento ${ }^{10}$.

\footnotetext{
${ }^{9}$ Segundo o artigo 81 da Lei de Execução Penal, compete ao Conselho da Comunidade in verbis: I - visitar, pelo menos mensalmente, os estabelecimentos penais existentes na comarca; II - entrevistar presos; III apresentar relatórios mensais ao Juiz da execução e ao Conselho Penitenciário; IV - diligenciar a obtenção de recursos materiais e humanos para melhor assistência ao preso ou internado, em harmonia com a direção do estabelecimento.

${ }^{10}$ Embora não esteja nos objetivos deste ensaio, cabe citar a hipótese de que mesmo entre os movimentos sociais e populares e partidos políticos do campo da esquerda, os estudos acerca da problemática aqui tratada é incipiente. Isso quando não reforçam o papel das prisões. Segundo Conceição (2016, p. 77), a partir das reflexões de Karam (1996) acerca da esquerda punitiva, "a primeira reivindicação repressora da esquerda foi o combate à criminalidade dourada: extensão da reação punitiva a condutas tradicionalmente imunes à intervenção do sistema penal realizada por agentes do poder político e do poder econômico. Em segundo instante, após a esquerda assumir o poder político, envelhecer, perder a utopia da transformação social e querer uma estabilidade material (não necessariamente nessa ordem), seria o enfrentamento à criminalidade
} 


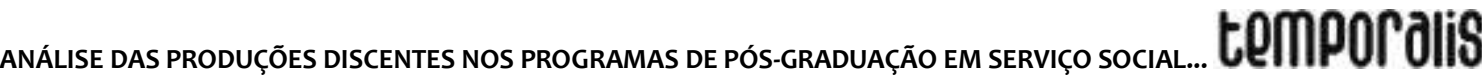

- Imigrantes Presos: Em 2014, 91\% dos imigrantes presos não estavam em alas ou celas exclusivas; $60 \%$ das unidades prisionais informaram desconhecer a nacionalidade dos imigrantes presos; Paraguai, Nigéria e Bolívia agregaram quase a metade das nacionalidades dos imigrantes presos; a cada dez imigrantes presos cinco eram provenientes da América; a região Nordeste registrava os maiores índices de presos de nacionalidade europeia; São Paulo era recordista de imigrantes presos (BRASIL, 2014). Em 2014, eram 2.784 imigrantes presos, que passaram a ser 2.606 em 2016 (BRASIL, 2017); o Levantamento Nacional de Informações Penitenciárias (INFOPEN) de 2016 expôs pouca mudança no quadro em questão em relação ao levantamento precedente. Os imigrantes privados de liberdade se defrontam cotidianamente com problemáticas pertinentes ao trabalho do Serviço Social e de outras áreas técnicas, a saber:

A dificuldade de obtenção de livramento condicional e de progressão de regime, dada a maior dificuldade dessas pessoas em atender às condições exigidas pela Lei de Execução Penal (como a obtenção de ocupação lícita, dentro de prazo razoável); a dificuldade em receber visitação e manter contato com a família; a carência à assistência consular; as dificuldades relacionadas à barreira linguística, como a falta de acompanhamento jurídico; o desconhecimento das regras disciplinares e do processo de execução penal (BRASIL, 2014, p. 60).

Parte desses dados, porém, são conflitantes com os do Ministério Público (BRASIL, 2016). Embora haja concordância em relação à leve queda da quantidade de imigrantes presos, diverge-se em relação ao número absoluto, pois, para o Ministério Público, enquanto em 2014 a quantidade era de 3.148 (e não 2.784 informados no INFOPEN), em 2015 reduziu-se para 3.035, dentre os quais 181 não se expressavam em português. O Estado de São Paulo, que recebera notificação a partir da Lei de Acesso à Informação para informar a quantidade de imigrantes presos em 2014 ao Departamento Penitenciário Nacional (DEPEN), parece ter subnotificado sua população imigrante privada de liberdade: enquanto para o DEPEN informou a quantidade de 1.796 imigrantes, os dados do Ministério Público apuram 2.133 em 2014 e 1.997 em 2015.

- A diversidade étnica e racial: Segundo o Ministério da Justiça (BRASIL, 2014), apenas $62 \%$ das unidades prisionais relataram ter condições integrais ou parciais de informar a raça ou etnia dos presos, apresentando uma amostragem de $45 \%$ da população carcerária. A tendência, porém, é a seletividade penal, no qual a cada três presos, dois são negros (pretos ou pardos). Esta seletividade é ainda mais perversa na região Sudeste, que registra $42 \%$ de negros em sua população geral, enquanto a população carcerária é composta por $72 \%$ de negros. Por outro lado, segundo o Ministério da Justiça e Segurança Pública (BRASIL, 2017), em 2016, a amostragem

\footnotetext{
de massas e à criminalidade organizada: o primeiro são os crimes de roubo e furto, para ela uma grande preocupação para quem quer gozar dos privilégios da estabilidade material; o segundo é identificado na atuação dos varejistas de drogas ilícitas, na violência policial e na corrupção. O limite dessa tese é o englobamento da esquerda, como se fosse uníssona, no bojo de um posicionamento político alinhado e afinado com a agenda neoliberal. Assim, a sua tese representa uma excelente representação ideal de um movimento real de setores que se autoproclamam de esquerda. Porém, não podem ser considerados representantes da totalidade da esquerda".
}

Temporalis, Brasília (DF), ano 19, n. 37, p. 172-187, jan./jun. 2019. | ISSN 2238-1856 
em relação à raça ou etnia dos presos foi de $72 \%$ da população carcerária total, cujo percentual de negros elevou-se para 64\%. Em relação à questão indígena, em 2014, 7,89\% das unidades prisionais informaram ter indígenas presos (112 unidades prisionais). Entretanto, apenas 46 unidades prisionais souberam informar a identidade linguística e a origem dos indígenas, assim como $91 \%$ das unidades prisionais não destinavam alas ou celas exclusivas aos indígenas (BRASIL, 2014). Em relação ao ano de 2016, o Ministério da Justiça e Segurança Pública (BRASIL, 2017) divulgou dados escassos da realidade dos indígenas no sistema prisional brasileiro. O Ministério Público (BRASIL, 2016), por sua vez, informa um crescimento de presos indígenas entre 2014 e 2015, 403 e 479 indígenas presos, respectivamente, concentrados nas regiões Norte (38\%) e Centro-Oeste (39\%).

- A privatização, terceirização e parcerias público-privadas da administração/gestão e dos serviços e assistências oferecidos: Dados do Ministério da Justiça de 2014 informam que $7 \%$ das unidades prisionais eram gerenciadas integral ou parcialmente por entes não públicos (parceria público-privada, cogestão ou por organização não governamental); em Minas Gerais, cerca de $22 \%$ das unidades prisionais tinham gestão não exclusivamente pública; eram nos serviços e assistências que se concentravam a entrega à iniciativa privada: quase $58 \%$ dos serviços e assistências eram terceirizados. Tanto o Ministério da Justiça e Segurança Pública em 2017 quanto o Ministério Público em 2016 não se ativeram a esta questão em seus relatórios e levantamentos.

- As organizações, coletivos e movimentos em defesa da pessoa privada de liberdade: Nenhum relatório analisado apresentou dados sobre essa questão. Sequer o Conselho da Comunidade recebeu preocupação.

- As condições de trabalho, vínculo empregatício e representação de classe: Conforme os dados do Ministério da Justiça (BRASIL, 2014), em 2014, um terço dos trabalhadores do sistema prisional brasileiro não eram agentes efetivos do quadro de funcionários (comissionado, terceirizado ou temporário); os assistentes sociais representavam $1,41 \%$ do total de trabalhadores do sistema; quase a metade (45,5\%) dos assistentes sociais não era efetiva; $36 \%$ das unidades prisionais não dispunham de sala de atendimento do Serviço Social; entre as que dispunham, 62\% eram compartilhadas com outro serviço; a proporção de presos para cada assistente social era de 386. Em 2016, segundo dados do Ministério da Justiça e Segurança Pública (BRASIL, 2017) percebe-se uma queda para 32,14\% de assistentes sociais não efetivos, assim como um quarto dos trabalhadores gerais não são efetivos. Percebe-se igualmente o contraste da relação preso para cada assistente social que aumentou de 386 para 520, entre 2014 e 2017. Os dados do Ministério Público (BRASIL, 2016) corroboram com os do Ministério da Justiça: em 2015, 61,54\% das unidades prisionais não apresentavam equipe de assistentes sociais; 52,92\% não contavam com recintos adequados para atendimento. Não há dados acerca da sindicalização de assistentes sociais lotados no sistema prisional.

- A saúde do trabalhador: Os relatórios analisados divulgam dados referentes à saúde da população carcerária, negligenciando por completo a saúde dos trabalhadores e as condições do ambiente de trabalho. 
A lacuna deixada pela ausência de trabalhos acerca das problemáticas supracitadas permite-nos indagar quanto a sua importância para o Serviço Social, no sentido de ampliar a sua autonomia relativa e de ressignificar sua relevância institucional, assim como a seguinte indagação: que papel caberia à profissão frente ao exposto nas lacunas?

Uma perspectiva qualitativa do estado da arte sobre as prisões no Serviço Social pode ser encontrada em Cavalcante (2015). Segundo o autor, os estudos das prisões no Serviço Social 11 têm "[...] pluralidade de concepções, visões de mundo, alinhamentos teóricometodológico e de posicionamentos políticos" (CAVALCANTE, 2015, p. 147). Ele apreende que alguns trabalhos realizam a reiteração do cárcere como resposta concreta à criminalidade. São trabalhos despolitizados, acríticos, simplistas, sem mediações teóricas e que, no fundo, corroboram com a criminalização da pobreza.

Outros artigos tentam exprimir uma perspectiva histórica, porém desconexa da totalidade, baseada, sobretudo, no livro clássico de Foucault (2014), Vigiar e Punir. Resgata-se, assim, uma determinada forma histórica de punição sem questionar o crime. Ao contrário, buscase elementos elucidativos justificadores do porquê do crime, sem contestar o que é e o que não é crime (CAVALCANTE, 2015).

Ao constituir padrões explicativos determinantes para o crime, realiza-se um flerte teórico com as criminologias etiológica e positivista, que se debruçam há décadas acerca das motivações do crime (CAVALCANTE, 2015). Processo que pode reforçar a estigmatização do pobre ou do jovem pobre.

Ainda conforme Cavalcante (2015), além de existir um questionamento singelo das instituições e dos processos de criminalização, tem-se nos trabalhos pouca apropriação da categoria da seletividade penal, assim como uma banalização da categoria criminalização da pobreza, adotada como uma espécie de senso-comum de esquerda, autoexplicativa, concebida em si própria, bem como sua apropriação enviesada, que pode corroborar com a própria criminalização.

Percebe-se, ainda segundo Cavalcante, além da ausência de interlocução interdisciplinar com outros campos do conhecimento, uma presença do sincretismo teórico do Serviço Social. Para o autor em referência, a presença do ecletismo, que é a face do sincretismo do Serviço Social no seu sistema de saber, conjuga elementos críticos e conservadores na mesma análise.

No âmbito da reincidência, Cavalcante (2015) apreende, nos trabalhos pesquisados, a existência de consenso sobre o papel das desigualdades sociais na reincidência e o caráter violento da prisão, no entanto, sem uma crítica estrutural no sentido de articulá-los com a sociedade de classes (CAVALCANTE, 2015). Igualmente, segundo o autor, existiria uma

\footnotetext{
${ }^{11}$ Este estudo é parte da dissertação de mestrado do autor, sob a orientação de umas das principais referências da problemática em questão no Serviço Social, a professora doutora Miriam Krenzinger Azambuja Guindani. No referido estudo, o autor analisa os anais, entre 2003 e 2013, do Congresso Brasileiro de Assistentes Sociais (CBAS) e o Encontro Nacional de Pesquisadores em Serviço Social (ENPESS), considerados os principais eventos científicos da profissão. Ele adota a metodologia quanti-qualitativa no desenvolvimento do trabalho. Aqui, apresentam-se apenas os dados qualitativos referentes ao sistema prisional. Para mais detalhes, cf. Cavalcante (2015).
}

Temporalis, Brasília (DF), ano 19, n. 37, p. 172-187, jan./jun. 2019. | ISSN 2238-1856 
expectativa ingênua dos autores dos artigos analisados na retórica da "ressocialização" e "reeducação", que aparecem como ineficazes devido às condições prisionais; pontualmente são vistos trabalhos com perspectivas que questionam as referidas retóricas e, com isso, contestam esta ingênua expectativa.

No sentido de articular o sistema penal com a conjuntura político econômica, com a crítica ao Estado e à estrutura de classes, Cavalcante (2015) percebe, nos artigos analisados, uma escassa problematização do neoliberalismo, da reestruturação produtiva, da mundialização e da financeirização do capital. Quando estas questões são problematizadas percebe-se um eurocentrismo nas análises, cuja fundamentação teórica é baseada em Loic Wacquant. Haveria, portanto, uma ausência de mediação com a particularidade brasileira (CAVALCANTE, 2015).

Por fim, Cavalcante (2015) considera que raros são os trabalhos que abordam uma perspectiva anticapitalista, que estabeleça nexo entre a estrutura e a superestrutura da sociedade polarizada em classes no sentido de revolucionar o sistema penal, suas agências e seus códigos, no horizonte de construir novas formas de resoluções de conflitos, calcada em uma sociedade humanamente diferente, socialmente igual e totalmente livre.

\section{CONSIDERAÇÕES FINAIS}

Escassez de produções sobre o lócus profissional em questão, concentração de produções em determinados temas e regiões, incipiência de produções sobre o trabalho profissional no referido lócus e lacuna de debates importantíssimos são os resultados parciais da pesquisa documental sobre o estado da arte nas pós-graduações em Serviço Social no Brasil, entre 2014 e 2017, sobre o sistema prisional. Romper com a persistência da lateralização de produções sobre o trabalho profissional no stricto sensu, igualmente, perdura-se como desafio para as próximas produções, assim como um estudo qualitativo das dissertações compiladas.

Revela-se, assim, uma despreocupação por parte das produções em se debruçar em um dos elementos constitutivos da violência estatal enquanto potência econômica. A violência como meio em uma sociedade polarizada em classes antagônicas sob o domínio da propriedade privada tem sua utilização distinta pelas classes sociais. A violência é a razão última do Estado no sentido de assegurar sua função ontológica de reprodução do capital (VÁSQUEZ, 2007). Ao se converter em ato, a violência estatal é ela própria uma potência econômica no sentido de assegurar a dominação de classes (VÁSQUEZ, 2007).

Repleta de contradições, as prisões, além de pouco estudadas pelo Serviço Social brasileiro, dificilmente são vistas enquanto um dos elementos estruturante desta sociabilidade. Portanto, quando o Código de Ética Profissional, de 1993, orienta a luta pela construção de uma nova ordem societária, defende-se no presente artigo que para esta luta perpassam necessariamente a denúncia, a deslegitimação e a defesa da abolição das prisões.

\section{REFERÊNCIAS}

ALMEIDA, N. L. T. Retomando a temática da "sistematização da prática" em Serviço Social. In: MOTA, A. E.; BRAVO, M. I.; et al. (Orgs.). Serviço Social e saúde: formação e trabalho profissional. São Paulo: Cortez, 2006.

Temporalis, Brasília (DF), ano 19, n. 37, p. 172-187, jan./jun. 2019. | ISSN 2238-1856 


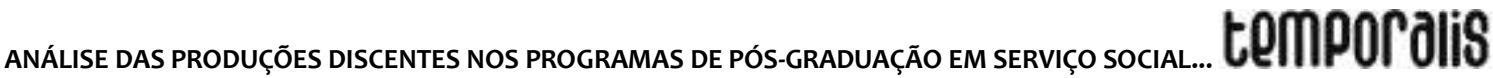

BRASIL. Ministério da Justiça. Departamento Penitenciário Nacional. Levantamento Nacional de Informações Penitenciárias - INFOPEN - junho de 2014. Brasília: MJ/DEPEN, 2014. Disponível em: http://www.justica.gov.br/noticias/mj-divulgara-novo-relatorio-doinfopen-nesta-terca-feira/relatorio-depen-versao-web.pdf. Acesso em: $1^{\circ} \mathrm{dez} .2017$.

BRASIL. Ministério da Justiça e Segurança Pública. Departamento Penitenciário Nacional. Levantamento Nacional de Informações Penitenciárias - INFOPEN - junho de 2016. Brasília: MJSP/DEPEN, 2017. Disponível em: http://depen.gov.br/DEPEN/noticias1/noticias/infopen-levantamento-nacional-de-informacoes-penitenciarias2016/relatorio_2016_22111.pdf. Acesso em: $1^{\circ}$ dez. 2017.

BRASIL. Conselho Nacional do Ministério Público. A visão do Ministério Público sobre o sistema prisional brasileiro. Brasília (DF), 2016.

CARVALHO, K. G. Religião e prisão: um estudo sobre a diversidade religiosa no sistema prisional do Rio de Janeiro. 2015. Monografia (graduação em Serviço Social)-Escola de Serviço Social da Universidade Federal do Estado do Rio de Janeiro, Rio de Janeiro, 2015.

CAVALCANTE, L. R. Serviço Social no Sistema Penal: uma análise crítica do conhecimento produzido e sistematizado pela categoria. 2015. 171 f. Dissertação (Mestrado em Serviço Social)-Programa de Pós-Graduação em Serviço Social da Universidade Federal do Rio de Janeiro, Rio de Janeiro, 2015.

CONCEIÇÃO, J. R. C. Serviço Social e punição: é possível um "Serviço Social punitivo"?. 2016. Monografia (Graduação em Serviço Social)-Escola de Serviço Social da Universidade Federal do Estado do Rio de Janeiro, Rio de Janeiro, 2016.

CONSELHO FEDERAL DO SERVIÇO SOCIAL (CFESS). Atuação de assistentes sociais no Sociojurídico: subsídios para reflexão. Brasilía (DF), CFESS, 2014.

COORDENAÇÃO DE APERFEIÇOAMENTO DE PESSOAL DE NÍVEL SUPERIOR. Relatório de Avaliação 2013-2016. Quadrienal 2017 - Serviço Social. Brasília (DF), 2017.

COORDENAÇÃO DE APERFEIÇOAMENTO DE PESSOAL DE NÍVEL SUPERIOR. Catalogo de Teses. Plataforma Sucupira. Disponível em: http://catalogodeteses.capes.gov.br. Acesso em: 24 jan. 2018.

GAMA, T. S. Religião e sistema penitenciário: um estudo sobre a assistência religiosa pentecostal no processo de reintegração da população carcerária do Estado do Rio de Janeiro. 2014. Dissertação (Mestrado em Política Social)-Programa de Pós-Graduação em Política Social da Universidade Federal Fluminense, Niterói, 2014.

GUINDANI, M. K. A. Tratamento Penal: a dialética do instituído e do instituinte. Revista Serviço Social e Sociedade, São Paulo: Cortez, n. 67, 2001.

KARAM, M. L. A esquerda punitiva. Revista discursos sediciosos: crime, direito e sociedade, Rio de Janeiro: Relume-Dumará, n. 1, ano 1, p. 79-92, jan./jun. 1996. 
LUKÁCS, G. História e Consciência de Classe: estudos sobre a dialética marxista. 2. ed. São Paulo: Editora WMF Martins Fontes, 2012. (Biblioteca do pensamento moderno).

ROCHA, S. N. R. A influência do ecletismo na produção teórica do Serviço Social na contemporaneidade. Tese (Doutorado em Serviço Social)-Programa de Pós-graduação em Serviço Social da Universidade Federal de Pernambuco, Recife, 2005.

SOUZA, M. T.; SILVA, M. D.; CARVALHO, R. Revisão Integrativa: o que é e como fazer. Revista Einstein, n. 8, p. 102-106, 2010. (1 Pt 1).

VÁSZQUEZ, A. S. Práxis e violência. In: VÁSQUEZ, A. S. Filosofia da práxis. 1. ed. Buenos Aires: Consejo Latinoamericano de Ciencias Sociales (CLACSO); São Paulo: Expressão Popular, 2007. (Coleção pensamento social latinoamericano). p. 371- 392.

\footnotetext{
João Rafael da Conceição

Assistente Social, graduado em Serviço Social pela Universidade Federal do Estado do Rio de Janeiro (UNIRIO), residente em Saúde da Mulher pelo Programa de Residência Multiprofissional da Universidade Federal do Rio de Janeiro (UFRJ). Mestre em Serviço Social pela Pontifícia Universidade Católica do Rio de Janeiro (PUC Rio). Especialista em Gestão Urbana e Saúde pela Fundação Oswaldo Cruz (FIOCRUZ). Especialista em Saúde Pública pela Fundação Oswaldo Cruz (FIOCRUZ). Membro da Comissão de Direitos Humanos, desde 2015, do Conselho Regional de Serviço Social do Estado do Rio de Janeiro (CRESS / $7^{\text {a }}$ Região). Foi representante externo do CRESS, em 2017, no Conselho de Segurança Pública do Estado do Rio de Janeiro (CONSPERJ). Atualmente, representa o CRESS no Conselho Estadual de Prevenção e Comitê à Tortura do Rio de Janeiro (CEPCT/RJ). Tem experiência na área de Serviço Social, com ênfase em Serviço Social no campo sociojurídico e na saúde. Estuda os seguintes temas: Serviço Social e violência, crime, sistema prisional, segurança pública e direitos humanos; Serviço Social e saúde, saúde mental e saúde do trabalhador.
} 